\title{
As contribuições das pesquisas em formação de professores/as para a compreensão de prática pedagógica como prática institucional
}

\author{
Guimarães, Orquídea ${ }^{1}$ \\ Santos, Maria do Carmo Gonçalo²
}

\begin{abstract}
Resumo
A prática pedagógica entendida como institucional, coletiva, intencional, articuladora das práticas discente, docente, gestora e epistemológica, na interface com os afetos e conhecimentos, intenciona a transformação humana e profissional dos sujeitos (SOUZA, 2009). Este trabalho busca conhecer as contribuições das pesquisas em formação de professores/as para a compreensão de prática pedagógica como prática institucional no EPENN e no PPGE/UFPE. Utilizamos a análise de conteúdo, que busca o significado latente dos dados (BARDIN, 2010) coletados a partir da pesquisa bibliográfica. O trabalho aponta a relevância da categoria prática pedagógica nos trabalhos de formação de professores/as; e ainda, a polissemia da sua utilização.
\end{abstract}

Prática pedagógica. Formação de Professores/as. Práticas.

\begin{abstract}
o
La práctica pedagógica entendida como institucional, colectiva, intencional, articulador de la práctica de los estudiantes, la enseñanza, la gestión y epistemológica, la interfaz con los afectos y el conocimiento, la intención de la transformación humana y profesional de los sujetos (SOUZA, 2009). En este trabajo se trata de comprender las contribuciones de la investigación en la formación docente para la comprensión de la práctica pedagógica como una práctica institucional en EPENN y PPGE / UFPE. Se utilizó el análisis de contenido, que busca el significado latente de los datos (BARDIN, 2010) recogidos de la literatura. El estudio pone de relieve la importancia de la categoría de la práctica docente en el trabajo del profesor; y, sin embargo, la polisemia de su uso.
\end{abstract}

La práctica pedagógica. Formación de Profesores. Prácticas.

\footnotetext{
1 Doutora em Educação pela UFPE - Núcleo de Formação de Professores e Prática Pedagógica/ Professora da Universidade Federal de Pernambuco - Centro Acadêmico do Agreste. orqgui@yahoo.com.br

2 Doutora em Educação pela UFPE - Núcleo de Formação de Professores e Prática Pedagógica/ Professora da Faculdade de Filosofia, Ciências e Letras de Caruaru. carmo1974@yahoo.com.br (81)99134-7189
} 


\section{Introdução}

A prática pedagógica, situada nas discussões mais amplas da educação e, mais especificamente, relacionada à formação de professores/as provoca pensar acerca das políticas públicas para a educação, destacando as políticas para os/as docentes, além de também envolver políticas relativas à gestão educacional.

Para Gatti; Barreto e André (2011) houve um crescimento nas pesquisas sobre a formação de professores/as e uma mudança nos objetos de pesquisa, nas últimas décadas focadas nos/as professores/as. As autoras dizem da importância de pensar as mudanças a partir da própria categoria e alertam para dois cuidados: continuar pesquisando sobre a formação inicial e não tomar o/a professor/a como o/a único/a responsável pela qualidade da educação.

Desse modo, situamos a prática pedagógica como uma categoria presente nos estudos acerca da formação de professores/as, que envolve e ultrapassa o olhar para o/a professor/a, revelando demandas maiores para a educação. Para tanto, compreender os sentidos da prática pedagógica e suas contribuições para a educação.

A prática pedagógica, situada como um conceito-chave, que contribui para a construção e revisão do sentido da escolarização, da profissão docente e da profissionalização do magistério. Aqui, esta prática é tomada como coletiva, institucional, plasmada nas práticas docente, discente, gestora, epistemológica, permeada por afetos, ou seja, o trabalho ampliado que abarca, dialoga e é constituído pelas idiossincrasias das práticas mais específicas (SOUZA, 2009).

Este artigo trata das contribuições das pesquisas em formação de professores/as para a compreensão de prática pedagógica como prática institucional. Para tanto, busca conhecê-las, identificando nos trabalhos de formação de professores/as a presença e os sentidos atribuídos à prática pedagógica nas pesquisas realizadas pelo Programa de Pós-Graduação em Educação da UFPE (PPGE/UFPE) e as veiculadas no Encontro de Pesquisa em Educação do Norte e Nordeste (EPENN). O trabalho de síntese e análise destas pesquisas pode responder ao pressuposto de que há um interesse das 
pesquisas em tratar da prática pedagógica, como também, uma multiplicidade de compreensões acerca de prática pedagógica, que pode orientar as práticas institucionais e dos sujeitos.

A pesquisa como diálogo e aproximação da realidade, no trabalho com práticas sociais, revela a complexidade frente a sua dinamicidade, em busca da atitude reflexiva (MELUCCI, 2005). Entendemos que investigar acerca desta categoria contribui para a sua sistematização e para compreensão ampliada de sua natureza institucional, como considerada por Souza (2009), podendo assim repercutir em práticas que situem o todo da relação pedagógica. Nesse sentido, buscamos os significados que nosso objeto de investigação apresenta, situando-os num contexto que é o da produção científica e sua divulgação. Configurada como uma pesquisa de natureza bibliográfica, tomamos a Análise de Conteúdo, na perspectiva de Bardin (2010), como técnica que nos permitiu a aproximação aos sentidos atribuídos à prática pedagógica. Foram priorizadas as pesquisas que abordam a categoria prática pedagógica, produzidas pela Linha de Pesquisa Formação de Professores e Prática Pedagógica (20002008) e as veiculadas no GT Formação de Professores no EPENN (2001 a 2009). Este recorte temporal foi selecionado considerando o marco dos 30 anos do PPGE/UFPE.

Para seleção das pesquisas analisadas, recorremos aos seus resumos identificando as palavras-chave prática pedagógica, prática docente, trabalho docente, prática educativa, prática de ensino, atividade docente ou educativa, práxis pedagógica ou educativa. Além das palavras-chave, consideramos os títulos das pesquisas, ou ainda indicação de categoria indicada como fundamentação teórica. Identificados os trabalhos, retiramos aqueles que utilizavam apenas a categoria prática docente, sem fazerem referência à prática pedagógica.

No caso das pesquisas produzidas pelo PPGE/UFPE, a investigação realizada por Betânia e Silva; Silva Pinto, et al (2008) sobre os trinta anos de pós-graduação em educação da UFPE (1978-2008), nos subsidiou como fonte de dados, através do CD com os resumos de teses e dissertações produzidos no Programa. A partir desse material identificamos 105 trabalhos produzidos 
pela Linha de Pesquisa Formação de Professores e Prática Pedagógica e destes, selecionamos 43 trabalhos, sendo 40 de mestrado e 03 de doutorado que utilizam a categoria prática pedagógica.

Para identificação das pesquisas do EPENN, recorremos aos Anais impressos e editados através de CD Rom, eles indicaram que do total de 568 trabalhos apresentados no GT 08 - formação de professores, 69 abordavam a prática pedagógica, o que representa pouco mais de $12 \%$ destes trabalhos. É importante destacar que dos 69 trabalhos, 14 são da UFPE, o que representa mais de $20 \%$ dos trabalhos apresentados, indicando não apenas um quantitativo significativo, mas que a prática pedagógica é uma preocupação nas pesquisas desenvolvidas pelo Programa, ao mesmo tempo em que se reconhece a necessidade de socializar as produções nele desenvolvidas.

Este trabalho sinaliza para a importância da categoria prática pedagógica nas produções acerca da formação de professores/as, bem como, a diversidade de concepções sobre esta categoria, e ainda, sua relação com as dimensões coletiva e institucional.

\section{A categoria prática pedagógica: sentidos e contribuições}

A discussão acerca da prática pedagógica articula-se, inicialmente, às categorias práxis e teoria e prática, uma vez que sua compreensão pode assumir caminhos distintos. A compreensão do conceito de práxis nos leva a estudar melhor os conceitos de teoria e de prática, tendo em vista que estes dois compõem e estruturam o conceito anterior.

Teoria e prática aqui são relacionadas à capacidade humana para produzir, criar, recriar, através da nossa condição cultural e histórica que nos possibilita pensar e agir motivados/as por uma intencionalidade.

Nesse sentido humanamente participativo, teoria assume um significado de intervenção, mas que ainda não se configura como ação concreta, prática, pois, mesmo situada, não representa atuação na realidade material. A teoria, enquanto fundamento, chave interpretativa do real, orienta o olhar para o que está "escondido" nas entrelinhas, para o que é distorcido pelo olhar superficial. Podemos denominar a teoria como atividade da consciência, por não implicar, 
por si só, em mudança da realidade, pois “ [...] quer se trate da formulação de finalidade, quer da produção de conhecimentos, a consciência não ultrapassa seu próprio âmbito; isto é, sua atividade não se objetiva ou materializa. (VAZQUEZ, 1977, p.193)

A teoria, portanto, demanda a presença da prática, não numa perspectiva de aplicação, de validação, mas de profunda coerência e diálogo. A prática nesta relação significa atividade interventiva na realidade. Entretanto, a prática nem sempre representa transformação, mesmo sendo concretização, objetivação, não pressupõe reflexão, o agir pode ser guiado pela repetição, adaptação, mesmice.

A prática como conceito relacional da práxis assume a mesma intencionalidade que motiva a teoria, agora no campo do concreto, do materialmente transformável. Assim como a teoria não transforma a realidade, a prática, sozinha, a prática pela prática, como ativismo "desinteressado" desemboca numa ação assujeitada, dependente de determinações externas apenas. Por isso, "[...] a prática não fala por si mesma e exige uma relação teórica com ela: a compreensão da praxis" (VAZQUEZ, 1977, p. 237).

O diálogo entre teoria e prática não impede que ambas as categorias tenham identidades próprias, pelo contrário, é revelador do quanto são diferentes, por isso mesmo dialéticas. A prática parece-nos anteceder e ser 0 chão da teoria, sem negar a importância desta, tendo em vista que sozinha não chegaria à práxis. Entendemos, portanto que a prática é o norte da teoria, porque esta surge do real, do concreto e retorna a ele, numa perspectiva dialética. Portanto, a prática requer teoria que a ajuda a enxergar melhor a realidade, e a direcionar o agir a partir de um protagonismo consciente, interessado, que situa o/a humano/a como sujeito da prática, não objeto.

Assim, teoria isoladamente não configura práxis, porque carece da materialização; prática só não alcança a perspectiva transformadora da práxis, porque é esvaziada de sentido. Práxis como atividades e pensamentos transformadores da realidade necessita da teoria que a sustente e da prática 
que a efetive. Esta compreensão dialética ${ }^{3}$ da práxis humana nos mostra que a compreensão da realidade, através de referenciais compartimentados, que não enxergam o todo, a relação, a dialética, a complexidade dos fenômenos sociais não é possível, pois não consegue captar, aproximar-se da totalidade e dinamicidade da realidade.

É nessa perspectiva de práxis que situamos a prática pedagógica tomando a ampliação e especificidades formuladas pelas discussões de Souza (2009), que sistematiza sua conceituação e considera como finalidade a perspectiva humanizadora da prática educativa construída por Paulo Freire.

Em Souza,

a concepção de PRÁXIS PEDAGÓGICA que se quer construir parte da suposição de que se trata de uma ação coletiva e institucional, portanto, ação de todos os seus sujeitos (discentes, docentes e gestores), permeada pela afetividade, na construção de conhecimentos ou de conteúdos pedagógicos (educacionais, instrumentais e operativos) que garanta condições subjetivas e algumas objetivas do crescimento humano de todos os sujeitos (SOUZA, 2009, p. 31, destaque do autor)

Assim, a prática pedagógica enquanto ação coletiva institucional e intencional, situada contextualmente, de modo que, o caráter institucional gera a realização de ações decididas sob orientações específicas consequentes dos interesses coletivos, organizados a partir de concepções sobre qual seja o papel da educação, dos conhecimentos pedagógicos que a estruturam e das finalidades a serem atingidas. Desse modo, sendo coletiva e institucional, a prática pedagógica ao mesmo tempo ajuda a compreender e organizar a ação coletiva é por ela organizada.

Ao ser coletiva, a prática pedagógica se constitui através do agir de todos os sujeitos que compõem o espaço educativo, que dão materialidade às dimensões que a compõem de maneira interconectadas, e dizem de sua amplitude, influenciando na formação dos sujeitos. Para Freire (2001), isso ocorre em função de ser a prática educativa social e por isso envolve sujeitos

\footnotetext{
3“'A dialética não é o método da redução: é o método da reprodução espiritual e intelectual da realidade é o método do desenvolvimento e da explicitação dos fenômenos culturais partindo da atividade prática objetiva do homem histórico" (KOSIK, 1976, p. 32), através da cisão do único, do pensamento crítico e da submissão a exame.
} 
que, mesmo em sua dimensão individual, têm suas vontades relacionadas a uma situação que é coletiva e contextual.

Sendo institucional, a prática pedagógica se materializa através de ações intencionais e situadas contextualmente resultando e resultantes de um projeto formativo, de modo a atender às exigências da sociedade em cada momento histórico de maneira consciente. Nesse sentido, se constitui em tempo e lugar nos quais se realiza a educação, e por isso pode ser entendida como

processos educativos em realização, historicamente situados no interior de uma determinada cultura, organizados de forma intencional, por instituições socialmente para isso designadas implicando práticas de todos e de cada um de seus sujeitos na construção do conhecimento necessário à atuação social, técnica e tecnológica. (SOUZA, 2009, p. 34)

Ou seja, é a prática pedagógica ao ser institucional, é socialmente reconhecida como espaço e tempo de formação articulada ao contexto social, vinculada a determinadas culturas, através de uma formação que não ocorre de maneira imediata, mas vinculada a um projeto educativo, que suscita movimentos relacionais, intencionais, organizados, não lineares.

É importante ressaltar que para Souza (2009), a instituição é síntese e não soma ou justaposição de sujeitos e estruturas, indicando que o trabalho coletivo não se reduz a ações parcelares, é a articulação entre os sujeitos engajados no trabalho coletivo, em um espaço ativo e de construção, situado no tempo e lugar historicamente construídos.

Para o autor, esse processo relacional contextualizado precisa favorecer a formação humanizada do/a humano/a e requer "superação do espontaneísmo da prática educativa no senso comum" isso porque ela é "prática educativa analisada reflexivamente, teorizada e realizada pelo coletivo institucional" (SOUZA, 2009, p. 69), de maneira argumentada e propositadamente. Desse modo, o autor entende ser a articulação teoria e prática direcionadora das ações da prática pedagógica.

Nessa direção é currículo construído e direcionado na e pela prática pedagógica, conduz a materialização das finalidades da educação, em especial a escolar, através da intencionalidade institucional entendida como construção 
coletiva. Desse modo, a intencionalidade e o contexto institucional influenciam na forma que se entende e vivencia a prática pedagógica. Gimeno Sacristán (2000) ao tratar do currículo como práxis estabelece sua relação com a prática pedagógica, afirmando que ela é institucional, que tem função socializadora e cultural, envolve múltiplas práticas e instituições.

Para Gimeno Sacristán (2000), o currículo como objeto em movimento, constitui uma prática articulada à prática pedagógica, institucional. E, ao destacar a forma recorrente de chamar prática pedagógica de ensino, associamos a Souza (2009), quando adverte a respeito do equívoco realizado por pesquisadores/as e pensadores/as da educação em tratar prática docente como prática pedagógica.

Em Santiago $(2006$; 2007) a prática pedagógica também vem articulada à discussão acerca do currículo, quando diz, apoiada na visão crítica, que o currículo pode ser abordado como uma prática pedagógica. Isto porque, segundo a autora, a prática pedagógica é espaço de construção e materialização de uma proposta pedagógica curricular, que tem a relação e o diálogo como categorias fundantes desse processo, reconhecendo os sujeitos educativos como construtores de conhecimento e não meros receptores/consumidores. Essa perspectiva sustenta-se na compreensão de que os sujeitos da educação são "históricos, situados, de relação, críticos, criativos e curiosos, cujos conteúdos da educação emergem da análise da realidade política e social" (SANTIAGO, 2007, p. 33).

Para Freire (2007), esse entendimento dos sujeitos da educação solicita a reflexão sobre a prática como necessária à transformação do saber desarmado, ingênuo, em um saber crítico e, para isso, a formação é convidada a assumir seu papel responsável em ensinar e vivenciar a reflexão crítica sobre a prática. Solicitar, pois, da agência formativa uma práxis pedagógica, a fazê-la pensar em sua reponsabilidade formativa em relação àqueles que serão incorporados ao mudo do trabalho com suas exigências, como também àqueles que precisam viver com dignidade plena de vida (SOUZA, 2009). Para isso, o autor sinaliza que a agência formadora seja percebida como espaço de formação, pesquisa (entendida enquanto atitude dos profissionais da formação 
e enquanto atividade acadêmica) e atualização docente, possibilitando a ressocialização, que ocorre mediante o confronto com a realidade social, resultando em recognição e em reinvenção 4 .

Freire (2001) afirma que a prática educativa é um fenômeno humano e que o humano se torna humano através das relações que estabelece contextualmente, em função de que "este ser que vive em si mesmo, a dialética entre o social, sem o que não poderia ser e o individual, sem o que se dissolveria no puro social, sem marca e sem perfil ${ }^{5}$, então concordamos que a prática educativa pode favorecer a humanização do humano, o que revela uma intencionalidade, um posicionamento político. É compartilhando dessa perspectiva que Souza (2009) considera ser a humanização do ser humano uma finalidade fundante da prática pedagógica.

$\mathrm{Na}$ perspectiva da humanização, a afetividade é entendida como norteadora da prática pedagógica, expressa através do querer bem, e por isso, necessita um trabalho rigoroso, que não se limita a ações de aplicação de técnicas e normas, ou seja, ações permeadas pela afetividade implicam comprometimento, cuidado, zelo com o outro, com o conhecimento, visto que a afetividade é elemento necessário ao desenvolvimento de uma prática pedagógica que se diz preocupada com a humanização (SOUZA, 2009; FREIRE, 2007e SANTIAGO, 2006).

Desse modo, afetividade como atitude pedagógica direciona o lidar com o outro, com o contexto e com o conhecimento, ou seja, não desconsidera a importância deste último como equivocadamente pode se pensar. $E$, na direção de construir uma ideia síntese, consideremos a seguinte afirmação:

A práxis pedagógica, portanto, é interrelação de práticas de sujeitos sociais formadores que objetivam a formação de sujeitos que desejam ser educados (sujeitos em formação) respondendo aos requerimentos de uma determinada sociedade em um momento determinado de sua história, produzindo conhecimentos que ajudem a compreender e atuar

\footnotetext{
${ }^{4}$ Souza (2009) denomina recognição as mudanças realizadas nas formas de pensar e compreender a nós mesmos, aos outros, a natureza, aos elementos culturais e as instituições sociais. Reinvenção por sua vez se refere às mudanças que realizamos nas formas de agir e nas emoções. A ressocialização seria, portanto, o processo permanente de recognição e de reinvenção. (p. 200).

5 Freire (2001, p. 67).
} 
nessa mesma sociedade e na realização humana dos seus sujeitos. (SOUZA, 2009, p. 29, grifos do autor)

Assim, entendemos a prática pedagógica como sendo constituída, dentre outras coisas, de um movimento permanente que provoca a interação entre sujeitos sociais, situados num contexto que influencia a prática pedagógica intencional e por ela é influenciado, sendo espaço de construção e materialização de um projeto pedagógico curricular, impregnado de construções culturais, articulado através de práticas docentes, discentes, gestoras, dentre outras, com vistas à humanização de cada um.

\section{A presença e os sentidos de prática pedagógica nas pesquisas do PPGE e do EPENN}

As produções do PPGE/UFPE e as publicações no EPENN no período de 2000-2009 dizem da importância da explicitação da categoria prática pedagógica nos trabalhos acadêmicos, pois, a análise revela a preocupação com esta categoria presente em um quantitativo significativo de pesquisas, apresentando sentidos diversos.

É importante ressaltar que o Programa de Pós-Graduação em Educação da UFPE, ao longo de 30 anos (1978-2008) teve 500 dissertações e 37 teses defendidas (SACRAMENTO et al, 2008, p. 75). Atualmente está organizado em seis Linhas de pesquisa - Didática, Educação e Linguagem, Espiritualidade, Formação de Professores e Prática Pedagógica, Política Educacional, Teoria e História da Educação -, e oferta os cursos de Mestrado em Educação (desde 1978) e Doutorado em Educação (desde 2002).

Destacamos aqui a Linha de pesquisa Formação de Professores e Prática Pedagógica "investiga a formação de professores e a prática pedagógica em diferentes espaços educacionais e níveis e modalidades de ensino, na perspectiva da cultura, da profissionalização e dos saberes docentes, do currículo, e das representações sociais" (PPGE/UFPE) ${ }^{6}$.

Além do desenvolvimento de pesquisas através de suas diferentes Linhas, o referido Programa se preocupa com o processo de difusão do

${ }^{6}$ Disponível em:

$<$ http://www.ufpe.br/ppgedunova/index.php?option=com_content\&view=article\&id=322\&ltemid=25> Acesso em: maio/2016 
conhecimento através de atividades diversas, como a participação em encontros acadêmicos, como é o caso do EPENN no qual esteve presente em todas as suas reuniões.

Este Encontro de pesquisadores/as em educação, é bianual e organizado pelos Programas de Pós-Graduação e Núcleos de Pesquisa das regiões norte e nordeste. Dentre seus objetivos, visa fortalecer os programas de pós-graduação em educação e suas produções, através do aprofundamento do conhecimento sobre a educação que se realiza nas respectivas regiões. Como também promover "espaços de comunicação, socialização e intercâmbio das pesquisas científicas e experiências acadêmicas vinculadas aos Programas de Pós-Graduação em Educação. ${ }^{7 "}$

E, mesmo se caracterizando como um encontro regional, o EPENN contribui com o campo da pesquisa no âmbito nacional, seja através de formas diversas de participação nos Encontros, seja através do fortalecimento da pesquisa no campo educacional. As pesquisas apresentadas em cada Encontro são vinculadas a um Grupo de Trabalho (GT). Ao longo da última década o GT 08 (Formação de Professores) apresentou o maior quantitativo de trabalhos selecionados e, apenas em 2003 teve um número inferior a cem trabalhos aprovados, sinalizando que o processo formativo, em suas diversas nuances, desperta uma elevada preocupação nas pesquisas educacionais.

A presença da categoria prática pedagógica e suas categorias afins (práxis educativa e fazer pedagógico) foi percebida como relevante nas produções do PPGE/UFPE, pois constituem objetos de pesquisa, objetivos, categorias teóricas e achados dos trabalhos do Programa. A sua utilização majoritária, enquanto objeto de pesquisa, indica a relevância dos estudos acerca da prática pedagógica.

No entanto, tais categorias nem sempre estão presentes nos eixos do resumo, de modo que, dos 40 trabalhos de mestrado analisados, apenas 5 trabalhos enfatizam a categoria prática pedagógica situando-a no título, nas palavras-chave e no resumo, enquanto 17 trabalhos só trazem a categoria no

7 Ver CD ROM, Início, página2, 18º EPENN (file:///D:/inicio.htm). 
interior resumo. Dos 3 trabalhos do doutorado, 2 mencionam no título, e o outro traz a categoria prática pedagógica nas palavras-chave e no resumo.

Apesar desta presença, prática pedagógica não aparece entre as categorias de pesquisa utilizadas por Betânia e Silva; Silva Pinto (2008) para organizar as dissertações e teses ao longo dos trinta anos analisados, como demonstra o quadro a seguir:

Quadro I - Categoria das Dissertações e Teses - 2000-2008

\begin{tabular}{|l|l|}
\hline Categorias & Quant. \\
\hline Políticas e Planejamento Educacionais & 41 \\
\hline Clientela Estudantil & 18 \\
\hline Agentes Educativos & 51 \\
\hline Currículo escolar & 31 \\
\hline Estratégias, Recursos e Avaliações de Aprendizagem & 50 \\
\hline $\begin{array}{l}\text { Sistemas, Instituições, Programas, Cursos e Movimentos } \\
\text { Educacionais }\end{array}$ & 26 \\
\hline História e Filosofia da Educação & 30 \\
\hline Outros & 13 \\
\hline
\end{tabular}

Fonte: Adaptado de Betânia e Silva; Silva Pinto (2008)

Mesmo considerando que prática pedagógica guarda relação com outras categorias, podendo assim estar contemplada nos temas destacados, essa opção pode influenciar na redução de sua relevância, inclusive ao considerar sua contribuição à formação e prática das instituições e sujeitos, sua relevância teórica, bem como, por estruturar uma das linhas de pesquisa deste Programa de Pós-Graduação. É importante salientar que Betânia e Silva; Silva Pinto (2008) justificam que estas categorias acima destacadas já haviam sido utilizadas em pesquisa organizada em 2004 por Freitas e Costa (apud BETÂNIA e SILVA; SILVA PINTO, 2008), o que nos indica a necessidade de sua atualização.

Destacamos ainda o fato de a categoria prática pedagógica ser utilizada nos trabalhos na Linha de Pesquisa Formação de Professores e Prática Pedagógica a partir do ano de 2001, e sua sistematização como prática institucional, constituída pelas práticas docente, gestora, discente e epistemológica, realizada Souza ocorre a partir de 2002 (SOUZA, 2009). 
No caso do EPENN, dos 69 trabalhos, 53 apresentam a prática pedagógica em seus objetos de pesquisa. No entanto, apenas 42 trazem uma discussão teórica específica sobre a categoria, e 3 apresentam-na como categoria empírica. É importante ressaltar que 2 trabalhos trazem prática pedagógica apenas no título e em 1 há a presença só na indicação das palavra-chave. Desse modo, ao mesmo tempo em que o quantitativo representa a relevância da categoria para as pesquisas em educação, parece também dizer da necessidade de maior rigorosidade nas produções acadêmicas.

Ao articularmos os trabalhos que abordam prática pedagógica no Programa e no Encontro de pesquisa em análise, percebemos algumas articulações. O gráfico a seguir possibilita visualizar a quantidade de trabalhos que mencionam a categoria em seus resumos, revelando sua maior evidência no ano 2006 com 9 trabalhos.

\section{Gráfico 1 Quantidade de trabalhos ano categoria Prática Pedagógica}

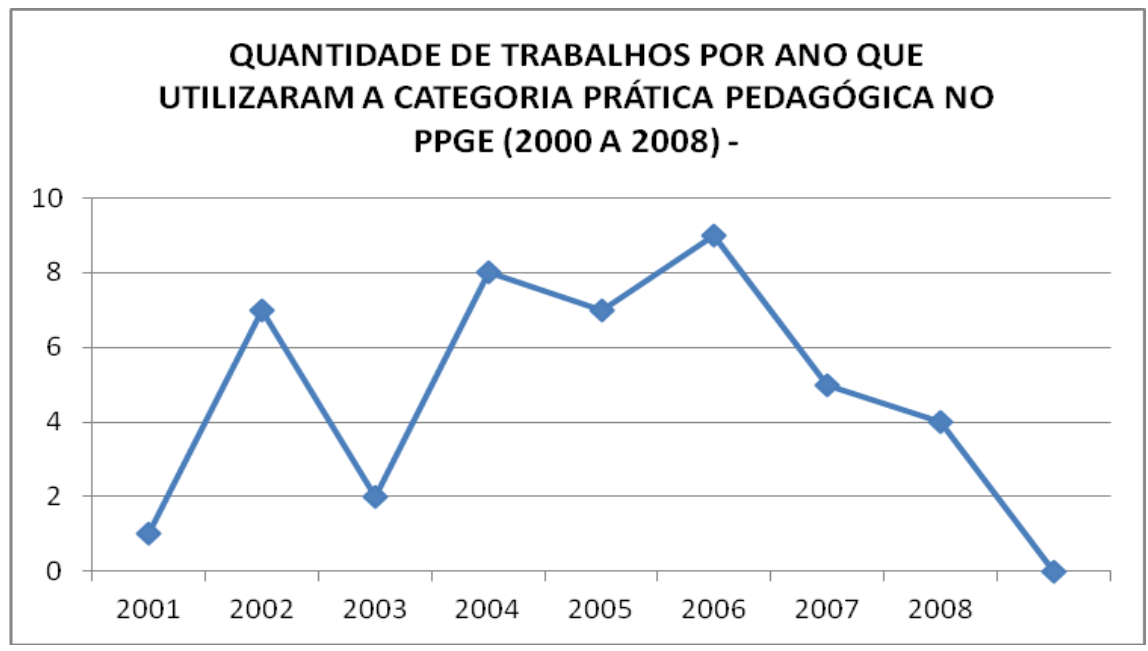

Fonte: Adaptado de Betânia e Silva; Silva Pinto (2008)

O gráfico mostra que a categoria é recorrente nos trabalhos do PPGE, sendo utilizada por quase uma década. E, nas pesquisas veiculadas no EPENN, essa presença também se apresenta de maneira significativa no período estudado. No quadro abaixo, temos o quantitativo de trabalhos que utilizam a categoria prática pedagógica e a identificação de quantos deles se originam do PPGE: 


\section{Quadro II -Trabalhos que utilizam a categoria prática pedagógica no EPENN (2001-2009) NO GT 08}

\begin{tabular}{|l|c|c|}
\hline Anos & GT 08 & № originados do PPGE/UFPE \\
\hline 2001 & 06 & 01 \\
\hline 2003 & 07 & 01 \\
\hline 2005 & 14 & 05 \\
\hline 2007 & 24 & 06 \\
\hline 2009 & 18 & 01 \\
\hline
\end{tabular}

No EPENN em 2005, dos trabalhos que tomavam a categoria prática pedagógica, quase a metade deles, era do PPGE/UFPE. Em 2007, esse quantitativo também se apresenta elevado. Assim, ao compararmos com o quantitativo de pesquisas desenvolvidas ao longo dos anos de 2000-2008 no PPGE/UFPE, percebemos a relação entre os dois espaços: em 2004 e 2006 há no Programa um aumento nos trabalhos que utilizam a categoria prática pedagógica, e sua presença aumenta nos EPENN dos anos subsequentes, ou seja, 2005 e 2007 respectivamente.

Destacamos também que a presença da categoria prática pedagógica nos espaços pesquisados, está presente de modo diversificado, seja em relação às temáticas dos objetos de pesquisa, seja em relação ao significado que apresentam. No PPGE/UFPE, os objetos envolvendo a prática pedagógica apresentaram-se vinculados a temáticas como movimentos sociais, coordenação e apoio escolar, coordenação pedagógica e componentes curriculares.

Nos trabalhos veiculados no EPENN, as temáticas diversas que tomam a prática pedagógica como categoria têm como predomínio a formação de professores/as, tanto inicial como continuada. Além dessa, aparecem com pouca incidência as temáticas: reforma agrária, educação ambiental, educação escolar e cultura planetária, cultura popular, cultura dos museus, cotidiano escolar, multimídia, uso do computador, saber docente e diferença. Essas temáticas ora estão como contexto no qual se insere o objeto, ora se apresentam como objeto e a prática pedagógica como seu contexto. 
Além disso, as pesquisas veiculadas no EPENN envolvem toda a Educação Básica, a Educação Superior, as modalidades de Educação de Jovens e Adultos e a Educação a Distância. E ainda, cursos como o de Pedagogia, Educação Física, Administração, Letras e Eletroeletrônica são espaços de investigação da prática pedagógica, seja no processo formativo, seja no exercício profissional.

Em relação aos significados, percebemos que alguns trabalhos utilizam a categoria prática pedagógica como palavra-chave, mas textualmente se apresenta apenas como termo que substitui prática docente, ou seja, como forma de organização textual de um parágrafo, com a preocupação de não repetir várias vezes o termo prática docente. Nessa situação, os trabalhos não apresentavam qualquer discussão ou mesmo menção quanto ao significado de prática pedagógica, como pode ser percebido na afirmação seguinte:

No que se refere às características no cotidiano da prática dos docentes, observamos que eles procuram exercer uma ação eficiente e que oportunize aos alunos uma aprendizagem significativa...; Dessa forma, observarmos que no cotidiano da prática pedagógica o docente deve ser um reflexivo, um pesquisador de sua própria prática e mobilizar diferentes saberes, (SOARES; MENDES SOBRINHO, 2007)

Os trabalhos apresentaram também uma predominância de compreender a prática pedagógica como sendo prática docente. Entendida como prática social, orientada por objetivos, finalidades e conhecimentos, relacional, destacando-se nela a relação entre os sujeitos professor/a e aluno/a, ambos percebidos de forma ativa, criativa, com ação produtora, tendo como preocupação central o ensino e a aprendizagem.

Em 20 dos 40 trabalhos de mestrado do PPGE/UFPE, a categoria prática pedagógica ressaltada é duplamente adjetivada: além de ser docente, há adjetivação em função da área de atuação do/a professor (prática pedagógica do professor de história, dos professores de inglês, do professor de geografia). Dos 03 trabalhos do doutorado, 01 concebe a prática pedagógica apenas como prática docente, outro trabalho trata da prática pedagógica institucional e o último situa a prática pedagógica a partir da aula universitária. 
Nas pesquisas socializadas pelo EPENN, a ênfase na prática pedagógica como prática docente destaca a preocupação com o processo de ensino e aprendizagem ganha centralidade na prática do/a professor/a, isso porque o ensino é entendido como o centro de sua ação. O trecho abaixo representa esta afirmação:

Neste estudo, define-se prática pedagógica como um conjunto de ações educativas construídas a partir de necessidades postas pelo real, sustentadas por teorias que embasam 0 processo ensino-aprendizagem. Assim, prática pedagógica comporta um fazer pedagógico, um fazer didático e competências docentes. (VALE, 2001).

A prática pedagógica entendida como prática docente é percebida ainda como prática que pressupõe uma relação teórico-prática, entendendo ser ela espaço de (re)construção de conhecimentos, espaço reificado da práxis, lhe dando objetividade, na perspectiva defendida por Vázquez, onde se articula teoria e prática, além de ser orientadora do currículo formativo. Como situamos no início deste artigo a prática pedagógica tratada como práxis envolve sua dimensão teórico-prática transformadora.

Outro sentido atribuído pelas pesquisas à categoria prática pedagógica o de prática coletiva, com preocupação centrada no desenvolvimento da aprendizagem. Esse sentido se aproxima da compreensão sistematizada por Souza (2009). Os trabalhos revelam ser reponsabilidade de todos os sujeitos que compõem a escola e/ou espaço educativo a formação dos estudantes.

Nos trabalhos do PPGE/UFPE, a dimensão da ação coletiva está presente sob diversas perspectivas, como prática pedagógica da escola, disciplina, prática social, movimentos sociais, enquanto prática gestora e de apoio escolar, como prática pedagógica da sala de aula e da escola, como fazer pedagógico, coordenação pedagógica, formação de professores e prática discente.

Alguns trabalhos do PPGE/UFPE e do EPENN explicitam a compreensão da prática pedagógica enquanto prática coletiva, por enfatizarem a presença de outros sujeitos nesta prática, além do/a professor/a, como diretores/as, coordenadores/as, entre outros/as. 
O sentido institucional também esteve presente na compreensão sobre prática pedagógica, ao se referirem ao contexto escolar, entendendo como a instituição influencia, organiza e acompanha a prática do/a professor/a, como no caso dos trabalhos que situam esta compreensão de forma ampla, conforme trecho deste resumo:

Procuramos analisar as práticas pedagógicas desenvolvidas na sala de aula e na escola de modo a identificar, nessas práticas, relações de poder que interferem nos resultados escolares e na vida escolar do aluno de forma geral, mas também focam a sua especificidade em relação ao seu objeto de pesquisa. (VALONES, 2003).

Para a autora a prática pedagógica desenvolve-se em dois espaços, na sala de aula e na escola. Quando a prática pedagógica é abordada como prática escolar, há uma maior aproximação à compreensão sistematizada por Souza (2009) sobre a prática pedagógica como prática institucional. Tratada nos resumos sob diversos significados (institucional, da escola, gestora, apoio escolar, coordenação pedagógica, discente) revela uma aproximação com o conceito definido pelo autor, uma vez que ultrapassa o limite da sala de aula e do trabalho do/a professor/a, envolvendo outros sujeitos e espaços. Entretanto, nos 40 resumos dos trabalhos de mestrado e 02 de doutorado do PPGE/UFPE, apenas identificamos 3 trabalhos de mestrado que citam Souza (2009) ao tratar da categoria prática pedagógica.

Destes trabalhos dois situam a definição utilizada (práxis/ prática pedagógica) a partir da teorização de Souza (2009), como é apresentado neste resumo: "Trabalhamos a relação com o saber a partir das ideias de Charlot (2000), compreendendo-a como elemento da parcialidade 'prática discente', desenvolvida de acordo com a concepção de Prática/Práxis Pedagógica teorizada por Souza (2009)". (ARAÚJO, 2008). Neste fragmento podemos perceber que a autora enfoca a prática discente como parcialidade, em seguida, fazendo menção ao conceito de prática/práxis pedagógica, à luz de Souza (2009).

Outro resumo de mestrado também situa a prática discente como componente da prática pedagógica, quando diz: "Este estudo, de natureza qualitativa, tem como principal objetivo compreender a repetência a partir dos 
significados que os alunos repetentes da escola pública atribuem a esse fenômeno no contexto da prática pedagógica onde ele ocorre" (PIMENTEL, 2005).

Esta compreensão merece destaque porque nem sempre a prática discente é considerada como dimensão da prática pedagógica, devido aos resquícios do "ensino bancário" (FREIRE, 1996), que situa o/a professor/a como o centro de uma relação autoritária e domesticadora.

Há ainda uma situação que merece destaque: ao tomar Souza como referência, o trabalho "O projeto pedagógico pessoal como instrumento de reflexão sobre a prática pedagógica no espaço escolar", da UFPI, minimiza a natureza institucional da prática pedagógica, como pode ser visto na afirmação a seguir:

Souza (2009) traz compreensão a respeito de prática pedagógica enquanto práxis, que embora ele a defenda como institucional, nos a entendemos como do(a) professor(a) também enquanto sujeito profissional docente. (...) recursos que possam ajudar o professor a lidar com esse desafio de forma a melhorar sua prática pedagógica entendida aqui com atividade intencional e planejada, dirigida envolvendo o aluno e que tem como objetivo promover aprendizagem. (SILVA, 2011)

Assim, apesar de considerar elementos discutidos por Souza, como a intencionalidade, a contextualização, o trabalho termina por distanciar-se da conceituação sobre prática pedagógica gestada pelo autor por desconsiderar ser ela institucional, além de não se reduzir à prática do professor.

Os trabalhos apresentam ainda algumas características para a prática pedagógica, devendo ser esta crítica, reflexiva, globalizada e humanizada, indicando ainda a formação para a democracia. Os trabalhos dizem ainda ser a prática pedagógica contextualizada, histórica, política e cultural, orientada por objetivos e finalidades, tendo como foco a descrição do cotidiano dos/as professores/as em suas ações de planejamento e realização do ensino, numa perspectiva dinâmica e relacional.

Percebem também, mas com menor incidência, a relação entre a prática pedagógica docente e currículo. Esta relação se caracteriza como sendo o currículo organizado para efetivação do ato pedagógico, que dá 
condições à realização da prática pedagógica docente, orientando suas finalidades.

A prática pedagógica como atividade humana também pode ser percebida nos trabalhos e Paulo Freire é a referência utilizada para essa discussão. A característica humana da prática influencia na compreensão relacional, histórica, subjetiva que a compõe. No entanto, a finalidade humanizadora da prática pedagógica não é abordada.

A afetividade também é sinalizada como direcionadora da prática pedagógica educativa, havendo a preocupação com as dimensões do sujeito que não se reduzem ao cognitivo, entendendo que a prática pedagógica docente influencia na subjetividade dos sujeitos:

A prática pedagógica, portanto, precisa considerar todas as experiências vivenciadas pelos alunos no cotidiano; precisa considerar a cultura em que esse aluno se encontra inserido e apreciar a cultura do professor e da escola. (REIS, 2005)

Podemos então considerar que a compreensão de prática pedagógica produzida pelas pesquisas no PPGE/UFPE (2000-2008) e as veiculadas nos trabalhos do EPENN (2001-2009), revela ser ela uma prática pedagógica humana por isso social e relacional, com intencionalidade formativa, tendo a instituição como influenciadora e espaço de sua efetivação, dizendo, portanto, de sua característica coletiva e institucional, mesmo que estes se limitem à preocupação com a aprendizagem e não com um projeto mais amplo de instituição. Uma prática orientada teoricamente, que tem como principal objetivo garantir a efetivação do ensino e aprendizagem nos diversos níveis e contextos formativos.

\section{Considerações Finais}

Este estudo nos leva a considerar que as pesquisas realizadas no campo da formação de professores/as, tanto no PPGE/UFPE (2000-2008) como as socializadas no EPENN (2001-2009) se preocupam com a categoria prática pedagógica como categoria teórica de modo enfático e em um quantitativo significativo. Isso se revela através de sua presença e dos sentidos tomados.

Apesar de predominantemente não conceituarem a prática pedagógica como prática institucional, estruturantes dessa compreensão na perspectiva sistematizada por Souza (2009) se fazem presentes nos trabalhos, mesmo 
quando a prática pedagógica é entendida como prática docente. Destacam-se os sentidos de ser a prática pedagógica, mesmo quando entendida como prática docente, social, coletiva, institucional em relação ao contexto e ao lugar que subsidia as condições para o desenvolvimento do ensino e da aprendizagem. Nesse sentido, se aproximam da definição apresentada por Souza (2009) sobre a categoria prática pedagógica, inclusive, ao destacarem a afetividade como norteadora de sua efetivação.

A compreensão ampliada de prática pedagógica contribui para 0 entendimento de ser institucional, intencional, coletiva, mesmo quando os trabalhos tomam a prática pedagógica como prática docente. No entanto, há necessidade de sua discussão teórica de maneira mais sistematizada, pois a característica institucional constituída pela prática pedagógica presente nos trabalhos não apresenta preocupação com um projeto coletivo, pedagógico de escola.

A partir dessas compreensões, consideramos que, se por um lado as pesquisas podem contribuir com uma visão mais ampliada da prática desenvolvida no espaço educativo, para além da transmissão de saberes apenas, por outro lado, os trabalhos aqui analisados ainda restringem a prática à prática docente. $\mathrm{E}$, ao entender o elemento institucional como influenciador $\mathrm{e}$ não como constituinte da prática pedagógica, influencia na visão que os sujeitos têm de sua relação com a instituição, do movimento de constituir e ser constituído pela prática pedagógica. Este trabalho provoca o interesse de estudos posteriores acerca da repercussão das concepções de prática pedagógica nas práticas das instituições e dos sujeitos da pesquisa.

\section{Referências:}

Anais XV EPENN. São Luiz, MA: UFMA, 2001. CD-ROM.

Anais XVI EPENN. Aracaju, SE: UFS, 2003. CD-ROM.

Anais XVII EPENN. Belém, PA: UFPA, 2005. CD-ROM.

Anais XVIII EPENN. Maceió, AL: UFAL, 2007. CD-ROM.

Anais XIX EPENN. João Pessoa, PB: UFPB, 2009. CD-ROM.

Anais XX EPENN. Manaus, AM: UFAM, 2011. CD-ROM.

BARDIN, Laurence. Análise de conteúdo. 4.ed. Edições Loyola, 2010. 
BETÂNIA e SILVA, Maria; SILVA PINTO, Andréa Carla Agnes e, et al (org..).

Programa de Pós-Graduação em Educação da UFPE: 30 anos de uma história (1978-2008). Recife: Ed. Universitária da UFPE, 2008.

FREIRE, Paulo. Pedagogia da autonomia: saberes necessários à prática educativa. São Paulo: Paz e Terra, 1996. (Coleção Leitura).

Política e Educação. São Paulo: Paz e Terra, 2001

GIMENO SACRISTÁN, José. O currículo: uma reflexão sobre a prática. Tradução Ernani F. da F. Rosa. 3. Ed. Porto Alegre: Artmed, 2000.

KOSIK, Karel. Dialética do concreto. 2. ed. Trad. Célia Neves e Alderico Toríbio. Rio de Janeiro: Paz e Terra, 1976.

MELUCCI, Alberto. Por uma sociologia reflexiva; pesquisa qualitativa e cultura. Tradução de Maria do Carmo Alves do Bomfim. Petrópolis, RJ:Vozes, 2005.

REIS, Maria da Conceição dos. A relação: prática pedagógica e cultura popular. In: Anais XVII EPENN. Belém, PA: UFPA, 2005. CD-ROM. (GT 08)

SACRAMENTO et al, Linhas de pesquisa, defesas realizadas e temas. In: BETÂNIA e SILVA, Maria; SILVA PINTO, Andréa Carla Agnes e, et al (orgs.). Programa de PósGraduação em Educação da UFPE: 30 anos de uma história (1978-2008). Recife: Ed. Universitária da UFPE, 2008.

SANTIAGO, Maria Eliete. Campo curricular, prática pedagógica e pedagogia freireana. In: Olhando o caleidoscópio: a escola em movimento. Ano 36 - Jan/mar, 2007.

Perfil do educador/educadora para a atualidade. In: BATISTA NETO, José. SANTIAGO, Maria Eliete (orgs.). Formação de professores e prática pedagógica. Recife: Fundação Joaquim Nabuco, Ed. Massangana, 2006. (pp. 113 119).

SILVA, Arlete Fragas da O projeto pedagógico pessoal como instrumento de reflexão sobre a prática pedagógica no espaço escolar. In: Anais XX EPENN. Manaus, AM: UFAM, 2011. CD-ROM. (GT 08).

SOUZA, João Francisco de. Prática pedagógica e formação de professores. Organizadores: NETO; José Batista; SANTIAGO, Eliete. Recife: Ed. Universitária da UFPE, 2009.

SOARES, Maria de Fátima Cardoso; MENDES SOBRINHO, José Augusto de Carvalho. A importância do saber experiencial no contexto das práticas pedagógicas de professores das séries iniciais do ensino fundamental. In: Anais XVIII EPENN. Maceió, AL: UFAL, 2007. CD-ROM. (GT 08).

VALE, Antonia Marques. Prática Pedagógica reflexiva: uma proposta de mudança para professores de $1^{\text {a }}$ série do ensino fundamental. In:Anais XV EPENN. São Luiz, MA: UFMA, 2001. CD-ROM. (GT 08).

VALONES, Neide Maria Alves. O poder disciplinar na relação pedagógica no cotidiano escolar. Recife, 2003. 216 f.Dissertação (Mestrado em Educação) Universidade Federal de Pernambuco.

VÁZQUEZ, Adolfo Sánchez. Filosofia da Práxis. Trad. Luiz Fernando Cardoso. 3. ed. Rio de Janeiro, Paz e Terra, 1977.

XVI EPENN. Anais do XVI Encontro de Pesquisa Educacional do Norte e Nordeste. São Cristóvão: UFSE, Pró-Reitoria de Pós-Graduação e Pesquisa, Núcleo de Pós-Graduação em Educação: Editora UFS, 2003. 
XVII EPENN. Anais - Educação, ciência e desenvolvimento social. Belém, PA: UFPA, 2005. Vol. 01; 2A; 2B.

XVIII EPENN. Programação do 18 EPENN. Maceió, AL:UFAL, 2007.

XIX EPENN. Caderno de programação. João Pessoa, PB: Ed. Universitária UFPB, 2009.

XX EPENN. Anais - Caderno de resumo do $20^{\circ}$ Encontro de Pesquisa Educacional do Norte e Nordeste. NASCIMENTO, A. C. A. [et al] (org.). Manaus: Editora Valer, 2011. 